\title{
THE PERFECT STORM: WHY INFORMATION SYSTEMS (IS) FACULTY RULED ACADEMIA FROM 1995 TO 2000
}

\author{
Mark A. Ward, Southern Illinois University Edwardsville, mward@siue.edu
}

\begin{abstract}
This study examines why IS faculty were able to command sizeable resources from the academic community from the mid-1990s until 2000. A convergence of several factors led to this remarkable historical phenomenon. Coinciding with the dramatic increase in IT employment and IS bachelor's and master's degrees with the so-called "dot-com" boom was a corresponding decrease in the awarding of IS PhDs. This study examines those factors and how they are related. In addition, the results and potential long-term ramifications of these unusual series of events on IS faculty and their students are also discussed.
\end{abstract}

Keywords: Information Systems Faculty, Information Technology Labor Market

\section{INTRODUCTION}

In the mid-1990s, a number of important events took place that placed IS faculty in the enviable position of commanding ample resources from the university. Among the many factors was a sharp rise in IT employment during a five-year period beginning in 1995. At the same time, the production of IS bachelor's and master's degrees also significantly increased. However, while demand for IS faculty was increasing (to meet the increased IS student body population), the number of IS PhDs declined during this same period. This study will examine what led to these events and the possible ramifications of this unusual convergence of phenomena in the academic community.

\section{The Rise of IT}

The modern Internet can trace its genesis to the first wide-area network established by the Advanced Research Projects Agency Network (ARPANET) in the late 1960s [1]. This network grew slowly over the following decades, being used mostly by the scientific and public sector (e.g., U.S. Department of Defense) communities. Significant technological changes took place in the mid-1990s. One of the most important of these was the creation of the Mosaic web browser, the first graphical user interface for the
Internet [2]. At the same time, the government deregulated the Internet and removed barriers to commercialization. These changes led to the beginning of the so-called "dot-com" boom and rapid growth of the Internet [3]. Not surprisingly, this resulted in an ever-increasing need for information technology (IT) personnel to create, maintain, and manage emerging information systems. At the same time, more managers were needed to supervise and lead these IT personnel.

\section{Growth Trends in IT Personnel and IS Faculty}

Relative to the growth of overall U.S. employment, U.S. IT employment rose at a much higher level during this boom period. By examining Figure 1, one can note that the average yearly increase in overall U.S. employment between 1995 and 2000 was 1.40 percent. During that same period, U.S. IT employment grew by 6.68 percent. The boom days of the dot-com industry came to an end in March 2000 when the NASDAQ composite index reached a peak of 5048.62 (10 March close) and began a precipitous fall. By 2002, U.S. IT employment had fallen by 10.70 percent over the previous year compared to the overall U.S. workforces' modest gain of .75 percent $[4,5]$.

Note that the NASDAQ is often used as a barometer of commercial high-technology industries because the majority of securities in this index represent hightechnology industries. Indeed, one can note the consistent relationship between U.S. IT employment and the NASDAQ by observing Figure 2 .

At the same time that both IT employment and the NASDAQ were on the rise, the number of IS bachelor's and master's degrees were also on the rise. Between 1995 and 2002, the number of IS bachelor's degrees grew by 104 percent. At the same time, the number of IS masters' degrees grew by 62 percent. Curiously, however, the number of IS PhDs shrank by 18 percent [6]. These relationships can be observed by examining Figure 3 . 


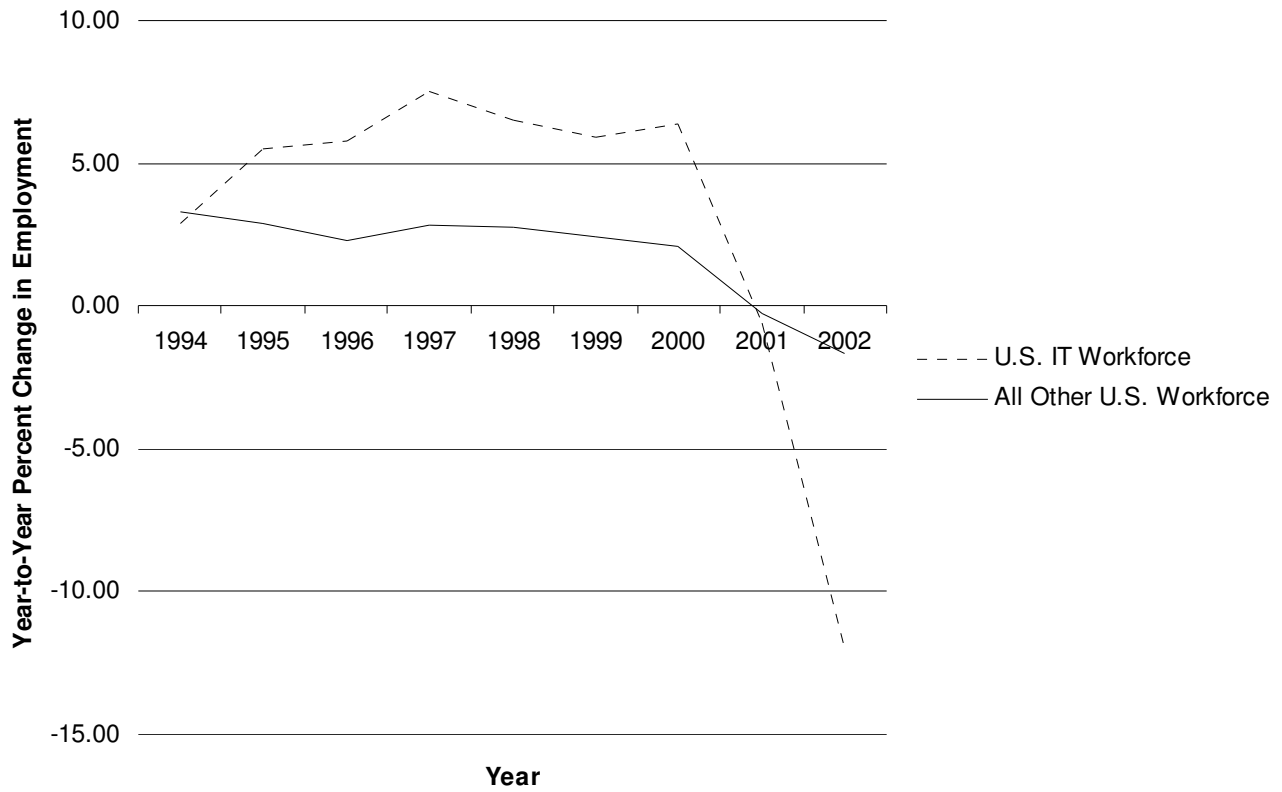

Figure 1. Percent Change in U.S. IT Workforce vs. All Other U.S. Workforce: 1994-2002

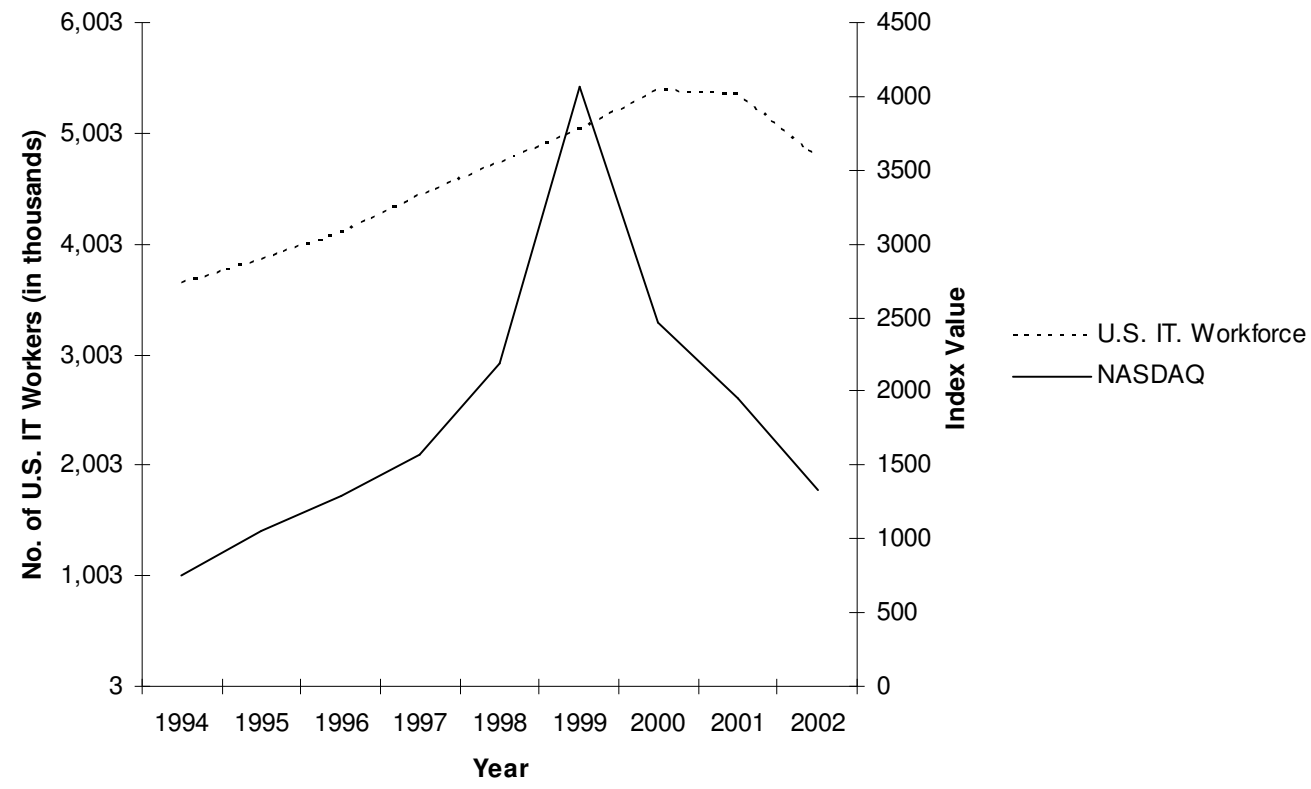

Figure 2. U.S. IT Workforce vs. NASDAQ Index: 1994-2002 


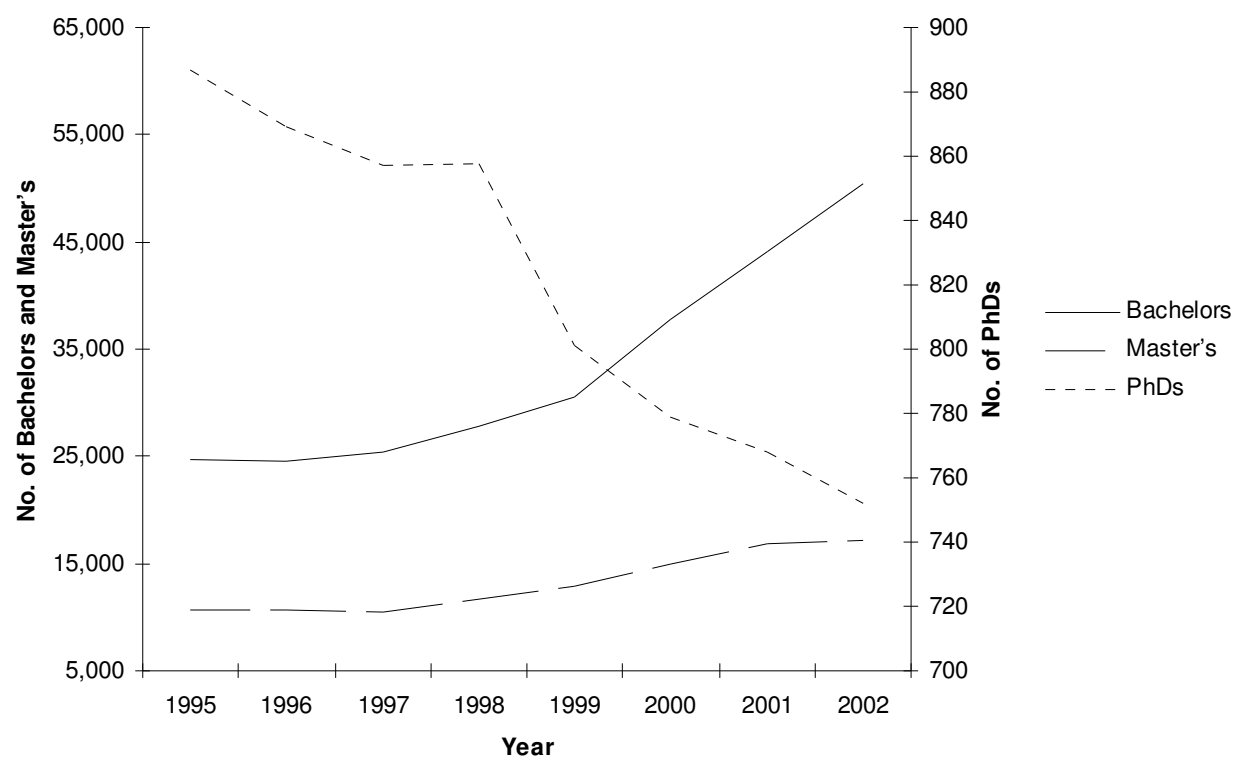

Figure 3. Number of IS Graduates: 1995-2002

Again, the number of IS PhDs steadily decreased between 1995 and 2002. Overall $\mathrm{PhD}$ production was more sporadic as shown in Figure 4. If one examines the number of all other non-IS $\mathrm{PhD}$ graduates between 1995 and 1998, there is an increase in the number of graduates. However, there is a decrease from 1998 to 1999 and a subsequent increase from 1999 to 2000.

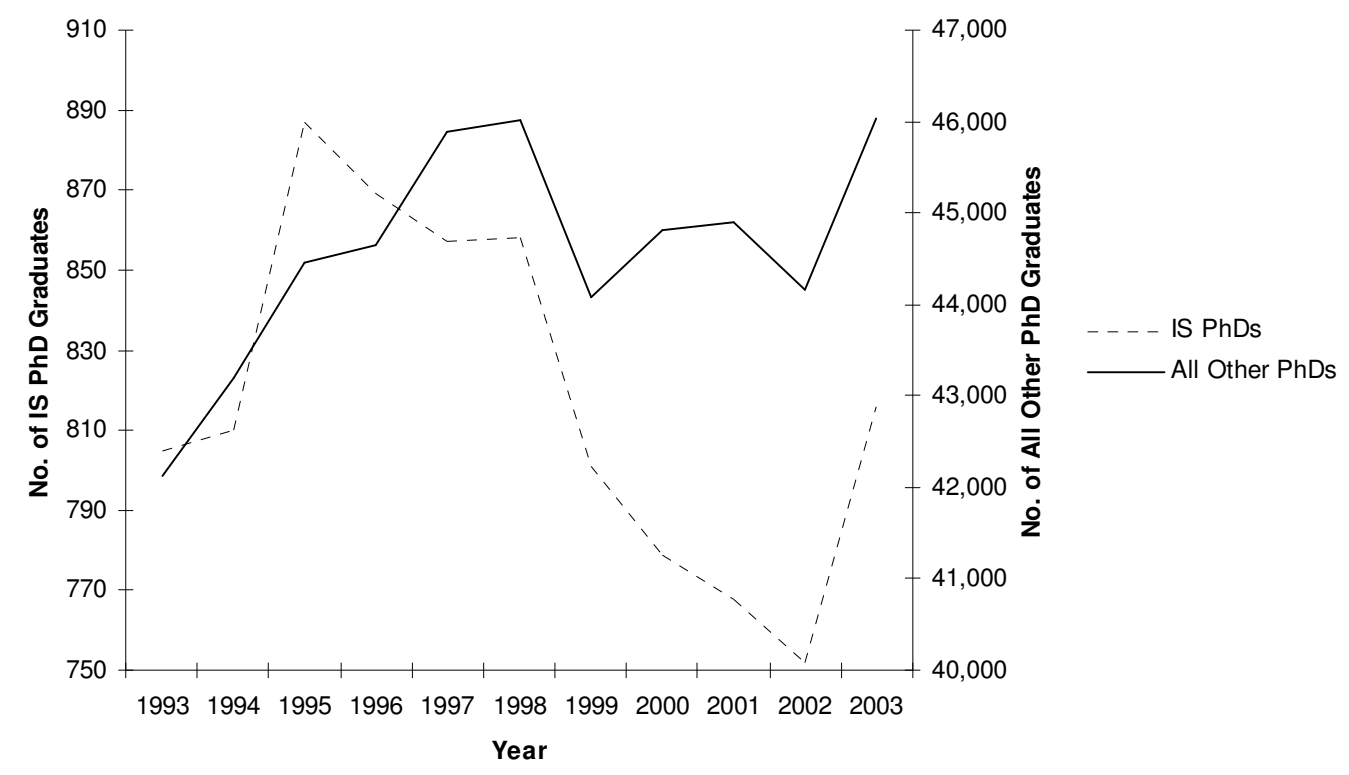

Figure 4. Number of Graduating IS PhDs vs. All Other PhDs: 1993-2003 
When one examines the IT workforce and IS PhD production, there appears to be an inverse relationship between these two groups, which is illustrated in Figure 5. However, such a relationship is less clear when one compares the rest of the U.S. workforce and all other PhDs during this same period, 1995 to 2002 as shown in Figure 6.

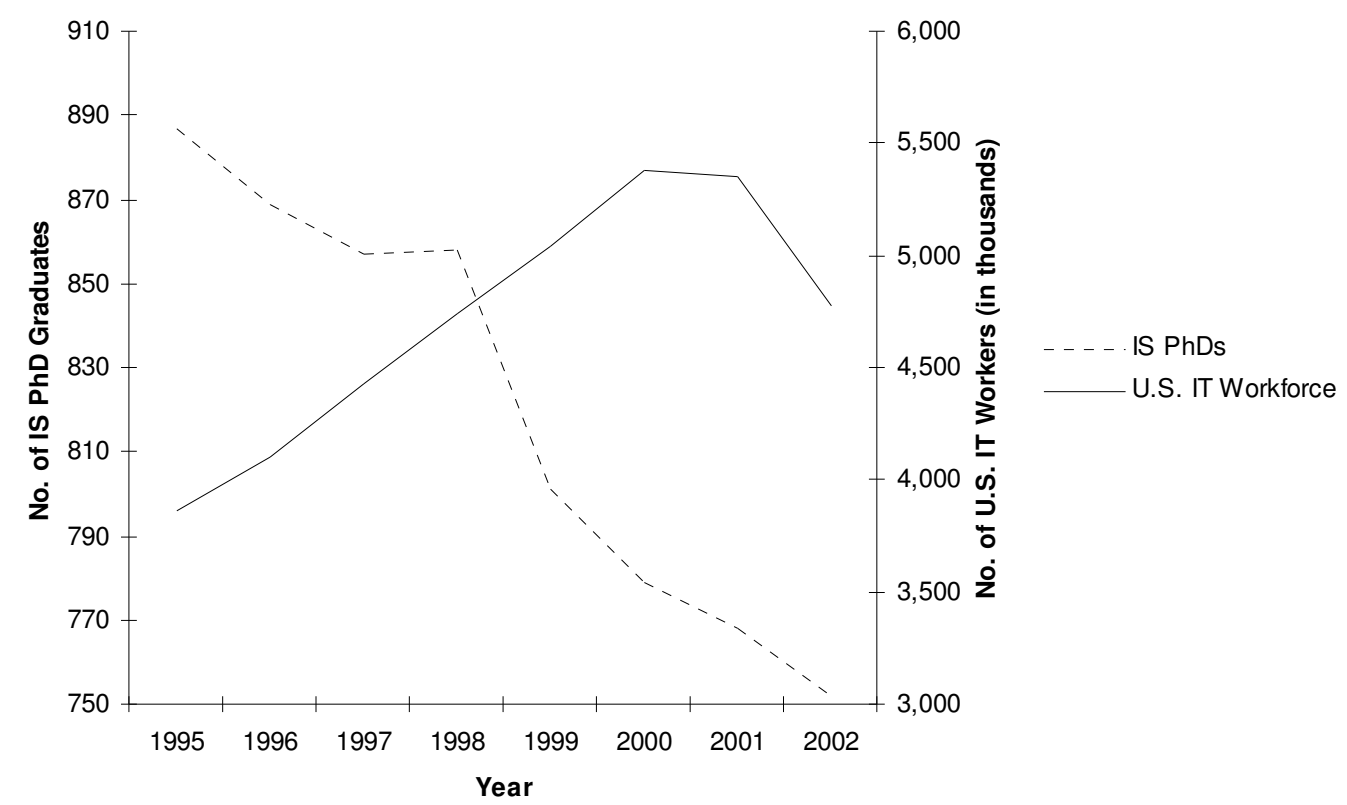

Figure 5. Number of Graduating IS PhDs vs. U.S. IT Workforce: 1995-2002

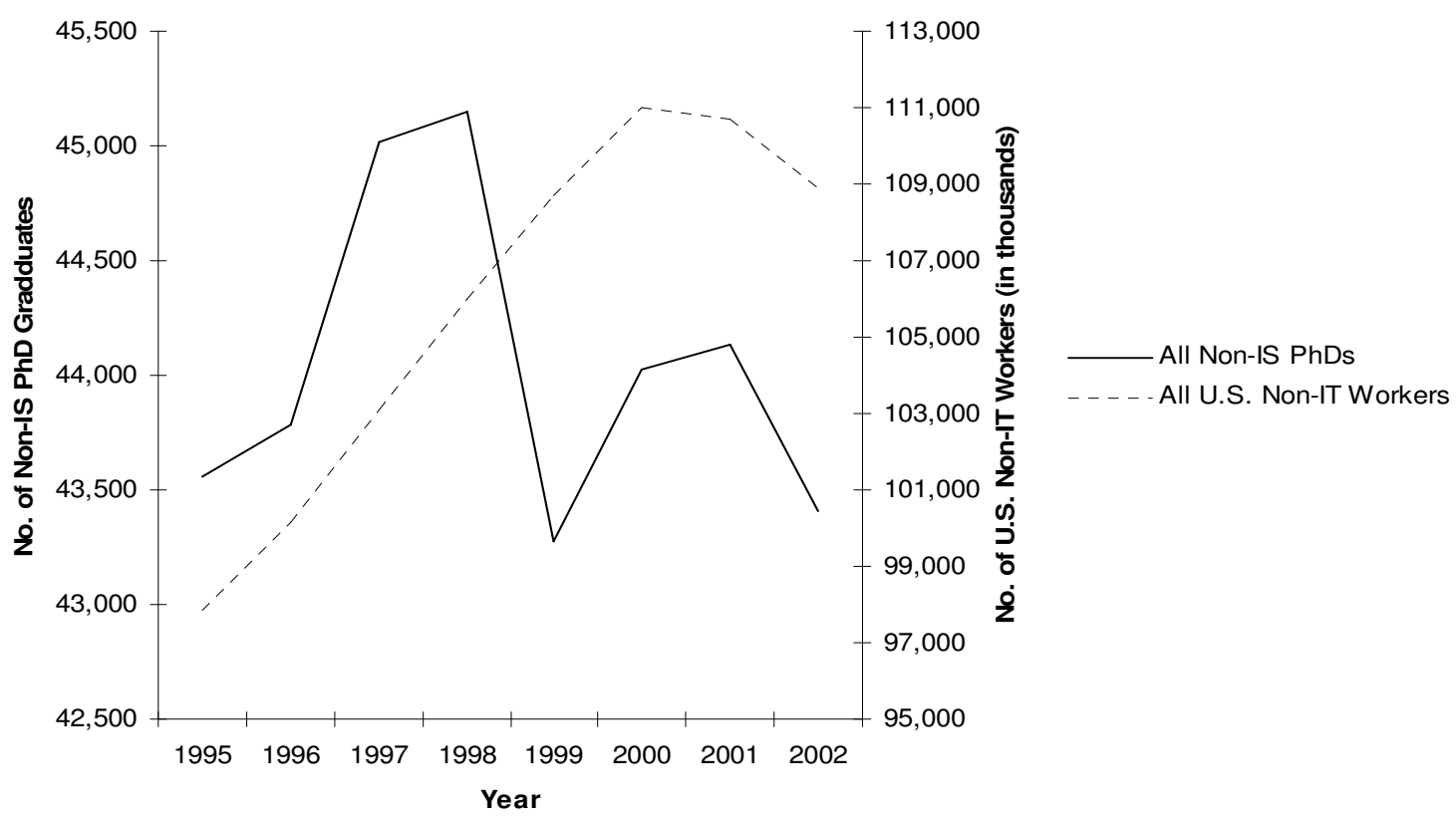

Figure 6. Number of Graduating Non-IS PhDs vs. U.S. Non-IT Workforce: 1995-2002 


\section{METHODOLOGY}

Although all of these data produce visually interesting results, this study also assesses how closely the data are statistically correlated. A Pearson product moment correlation coefficient was used for this purpose.

\section{RESULTS}

\section{U.S Workforce and PhD Production: 1995 to 2002}

There are several parameters of interest with respect to these particular data, which consists of the U.S. workforce (minus IT employees) and $\mathrm{PhD}$ graduates (minus IS graduates) between 1995 and 2002. When a Pearson product moment correlation coefficient is applied to determine the level of correlation between the number of $\mathrm{PhDs}$ and bachelor's degrees produced between 1995 and 2002, it creates a correlation coefficient of $\mathrm{r}=.30$ and is not statistically significant. Similarly, when the same statistic is applied to $\mathrm{PhDs}$ and master's graduates during this same period, it produces $r=.16$ and is not statistically significant. When examining the relationship between $\mathrm{PhDs}$ and the U.S. workforce also during this period, the Pearson product moment correlation coefficient is similarly statistically insignificant with $\mathrm{r}=.06$.

\section{U.S. IT Workforce and IS PhD Production: 1995 to 2002}

When a Pearson product moment correlation coefficient is applied to determine the level of correlation between the number of IS PhDs and IS bachelor's degrees produced between 1995 and 2002, it creates a correlation coefficient of $r=.93$ and is significant at the .01 level. When the same statistic is applied to IS PhDs and IS master's degrees during this same period, the correlation coefficient is similarly significant, $r=.96$, at the .01 level. When examining the relationship between IS PhDs and the U.S. IT workforce, the Pearson product moment correlation coefficient is statistically significant at .05 with $r=.83$. Notably, an obvious downturn in IT employment is evident in 2002. When that particular data point is eliminated from the Pearson statistic (1995 to 2001 only), the measurement yields $r=.95$ and is statistically significant at the .01 level.

\section{DISCUSSION}

This study found no statistically compelling relationship between $\mathrm{PhD}$ production and master's or undergraduate degrees education in general between 1995 and 2002. Similarly, no statistical correlation was found between $\mathrm{PhD}$ production and the general workforce during this same period. On the other hand, when one compares the number of IS $\mathrm{PhD}$ graduates to the number of master's or undergraduate degrees, a significant inverse relationship is evident. In addition, these data show the IS $\mathrm{PhD}$ graduation figures to be significantly inversely correlated to IT workforce levels between 1995 and 2002.

There seems to be no relationship between the number of PhDs and master's or bachelors degrees awarded. Further, there appears to be no relationship between the number of PhDs awarded and the U.S. workforce level. Hence, it could be inferred that the dot-com boom appears to have had no appreciable influence over the number of PhDs being produced. Of course, causality cannot be statistically ascertained using the Pearson product moment correlation coefficient. However, it seems reasonable to assert that if a cause-and-effect relationship is present between IS $\mathrm{PhD}$ production and the IT workforce numbers (as suggested by these data), it was the dot-com boom that was drawing the pool of doctoral candidates away from academia. At the same time the number of IS $\mathrm{PhD}$ graduates was declining, the number of IS master's and undergraduate degrees being awarded was increasing at roughly the same rate.

\section{CONCLUSIONS}

One reason the number of IS PhDs may have decreased during this period may have to do with the booming IT economy of the 1990s. Many individuals with an IS master's degree who otherwise would have pursued an IS $\mathrm{PhD}$ may have elected to enter the private sector to pursue an IT career instead of a career in academia. At the same time that individuals were electing to pursue non-PhD options, the need for IS PhDs was increasing because of increasing enrollment in the IS field. Hence, in a universe where supply is decreasing at the same time demand is increasing, those individuals who control the supply will command greater resources.

Interestingly, since 2002 IS enrollment has declined and continues to decline. The average industry is expected to grow its workforce by about $14 \%$ between 2005 and 2014. While it is true that the projected growth in the information sector is only expected to grow $12 \%$ during this same period, a more nuanced reading of these projections is needed. For example, several important sectors within the 
information sector are expected to grow at a rate that is much higher than the industry average. For instance, the software publishing component of the information industry sector is expected to grow by $68 \%$, which is only superseded by home healthcare services (69\%) and private educational support services $(79 \%)$. In addition, cable and subscription programming $(46 \%)$, Internet publishing and broadcasting $(43 \%)$, and computer systems design and related services $(39 \%)$ are also among the fastest growing sectors compared to all other industry sector averages (14\%) [7].

Since the information sector is expected to grow at a slightly slower rate than the average growth of the remaining sectors during the next few years, it is unclear whether or not the decline in IS enrollment will continue. However, given that certain sectors within IS are projected to have exponential growth, there must be a concomitant significant decline in other information sectors. For that reason, universities and colleges may find it likewise prudent to emphasize some courses and curriculums over others.

It should be pointed out, however, curriculum prioritization may not be as easy as deleting some courses and adding others. For example, the wired telecommunications carrier field is expected to decline by $31 \%$ between 2004 and 2014 [7]. At the same time, cable and subscription programming (as just mentioned) is expected to grow by $46 \%$ during this same time period [7]. What makes this situation complex is that both of these fields fall under the more general heading of telecommunications. Hence, one would not likely be inclined to deemphasize or eliminate an undergraduate networking and telecommunications course. Instead, it would probably be more prudent to stress cable and programming distribution (over wired telecommunications) under a broader undergraduate telecommunications course. Other courses in IS may require a similarly complex analysis to meet emerging industry trends.

\section{REFERENCES}

1. Ward, M. A. (2004). Internet diffusion public policy in the U.S.: A critique. Ethics \& Critical Thinking Journal, 18(4), 57-73.

2. Stallings, W. (2001). Business data communications (4th ed.). Upper Saddle River, New Jersey: Prentice Hall.

3. Ward, M. A. (2005). Publication trends in technology mediated learning (TML): A recent retrospective. Issues in Information Systems, 6(2), 238-243.

4. U.S. Department of Commerce. Economics and Statistics Administration. (2004, April). Digital Economy 2003: Technical Appendices. Washington, DC: Government Printing Office.

5. Bureau of Labor Statistics. (2006). Industry at a glance: Information. [online], Washington, DC: U.S. http://www.bls.gov/iag/information.htm

6. U.S. Census Bureau. (2005). Educational attainment. [online], Washington, DC: U.S. Available:

http://www.census.gov/population/www/socdem o/educ-attn.html

7. Bureau of Labor Statistics. (2006, Winter 200506). Industry employment. Occupational Outlook Quarterly, 49(4), 35-36. 